\title{
MECHANISMS AND EARLY WARNING OF DROUGHT DISASTERS Experimental Drought Meteorology Research over China
}

Yaohu li, Xing Yuan, Hongsheng Zhang, Runyuan Wang, Chenghai Wang, Xianhong Meng, Zhigiang Zhang, Shanshan Wang, Yang Yang, Bo Han, Kai Zhang, Xiaoping Wang, Hong Zhao, Guangsheng Zhou, Qiang Zhang, Qing He, Nı Guo, Wei Hou, Cunje Zhang, Guoju Xiao, Xuying Sun, Ping Yue, Sha Sha, Heling Wang, Tiejun Zhang, Jinsong Wang, and Yubi Yao

A major research project in China was launched to measure and model ecohydrometeorological processes for drought disasters and to disseminate multidisciplinary information by establishing a northern China drought information system.

AFFILIATIONS: LI, R. WANG, S. WANG, YANG, K. ZHANG, X. WANG, Zhao, Guo, Sun, Yue, Sha, H. Wang, T. Zhang, J. Wang, and YaOKey Laboratory of Arid Climatic Change and Reducing Disaster of Gansu Province, and Key Open Laboratory of Arid Climate Change and Disaster Reduction, Institute of Arid Meteorology, Chinese Meteorological Administration, Lanzhou, China; YuAN-School of Hydrology and Water Resources, Nanjing University of Information Science and Technology, Nanjing, and Key Laboratory of Regional Climate-Environment for Temperate East Asia, Institute of Atmospheric Physics, Chinese Academy of Sciences, Beijing, China; H. ZHANG-Laboratory for Climate and Ocean-Atmosphere Studies, Department of Atmospheric and Oceanic Sciences, School of Physics, Peking University, Beijing, China; C. WANG AND HaN-Key Laboratory for Semi-Arid Climate Change of the Ministry of Education, College of Atmospheric Sciences, Lanzhou University, Lanzhou, China; MENG - Cold and Arid Regions Environmental and Engineering Research Institute, Chinese Academy of Sciences, Lanzhou, China; northern China suffers from droughts the most. To understand drought mechanisms and mitigate drought risk, China launched a series of projects, including the Mechanism and Prediction of Major Weather and Climate Disasters (1998), Northern China Aridification and Human Adaptation (2005),
Z. ZHANG AND Q. ZHANG-National Meteorological Information Centre, Beijing, China; ZHou-Gansu Provincial Meteorological Bureau, Lanzhou, and Chinese Academy of Meteorological Sciences, Beijing, China; $\mathrm{HE}$-Institute of Desert Meteorology, Chinese Meteorological Administration, Ürümqi, China; Hou AND C. ZHANG - National Climate Centre, Beijing, China; $\mathrm{XIAO}$-Research and Development Center for New Techniques, Ningxia University, Yinchuan, China

CORRESPONDING AUTHORS: Yaohui Li, li-yaohui@I63.com; Xing Yuan, xyuan@nuist.edu.cn

The abstract for this article can be found in this issue, following the table of contents.

DOI:10.1175/BAMS-D-17-0029.I

In final form 14 September 2018

(C)2019 American Meteorological Society

For information regarding reuse of this content and general copyright information, consult the AMS Copyright Policy. 
and Energy and Water Cycle Variability under Global Warming and Its Impact on Climate Extremes over China (2008). In the past decade, China's drought projects expanded from national to global scales, aiming to obtain global background of regional droughts and aridification (Huang et al. 2016a,b).

Several decades of drought research have identified the variations and variability in the East Asian summer monsoon and Indian summer monsoon, the west Pacific subtropical high and South Asian high, the land surface over Tibetan Plateau, and El Niño-Southern Oscillation as important factors in drought occurrence over China. To monitor and predict droughts, several in situ and satellite observation-based drought indices have been developed [e.g., the comprehensive meteorological drought index (CI), surface water content index (SWCI), and vegetation condition index (VCI)], and meteorological drought prediction techniques have transitioned from statistical methods to numerical model-based statistical-dynamical forecasting methods.

However, most research has mainly focused on the cause and characteristics of droughts from the perspective of abnormal atmospheric circulations and oceanic conditions (Schubert et al. 2009; Hoerling et al. 2014; Trenberth et al. 2014; Wang et al. 2017) without comprehensive observational experiments or drought mechanism research focusing on the understanding of the entire processes, ranging from land-atmosphere interactions to agricultural (ecology) drought formation from a multidisciplinary perspective. Here, the following five research areas are highlighted to promote drought disaster studies:

1) Understanding the interactions among atmosphere, hydrosphere, and biosphere with respect to drought onset and recovery as well as the relationship between meteorological droughts and agricultural, hydrological, and ecological droughts that is critical to unraveling the mechanisms of drought disasters. While there are studies on individual types of droughts, the full chain of drought disaster evolution is not well understood.

2) Several physical processes that are unique over arid and semiarid regions (e.g., northern China), such as the soil water vapor-heat interaction that affects surface soil moisture variability, the effect of intermittent turbulence on boundary layer energy exchange, and the drought-albedo feedback with variable land cover, are often overlooked by many drought modeling studies.
3) The transition from stomatal to nonstomatal control of plant photosynthesis with the increase in drought severity cannot be reasonably represented in drought models without intensive observational experiments.

4) Integrated hydroclimate forecasting systems that incorporate both seasonal climate prediction information and initial land surface hydrological memory have become popular in recent years, but their performances need to be rigorously verified over the target areas with comprehensive hindcast experiments, especially for extreme drought cases.

5) Multisource drought information systems built on our understanding of drought disaster mechanisms, advanced drought prediction models, and the reasonable estimation of drought impacts as well as state-of-the-art observation techniques (e.g., radar, satellite remote sensing) have received wide attention among the global drought community, but these approaches are far from perfect given the comprehensive datasets and complicated dialogues across multiple disciplines.

To improve the drought adaptation capability over northern China for arid and semiarid climates, in 2015, China launched the Mechanisms and Early Warning of Drought Disasters over Northern China (DroughtEX_China) project, which is led by the China Meteorological Administration (CMA). Based on a series of regular, intensive, and specially designed observations as well as field experiments on the natural and manually controlled drought conditions, interdisciplinary and comprehensive drought research is being performed. This research will advance the understanding of the complicated dynamic processes of the onset and recovery of drought disasters, the characteristics of the water and energy cycles in the atmosphere-soil-vegetation system at multiple scales, and the relationship among meteorological, agricultural, and hydrological droughts. Moreover, technological advancements in accurate monitoring, risk assessment, and early warning for drought disasters are expected.

The DroughtEX_China project aims to 1) carry out interdisciplinary, comprehensive, and systematic field observational experiments to identify drought disaster mechanisms over northern China; 2) investigate the characteristics of the landatmosphere interactions from drought onset to recovery and model the link between meteorological droughts and drought disasters; 3 ) improve the parameterization schemes of land surface processes and atmospheric boundary characteristics for better 


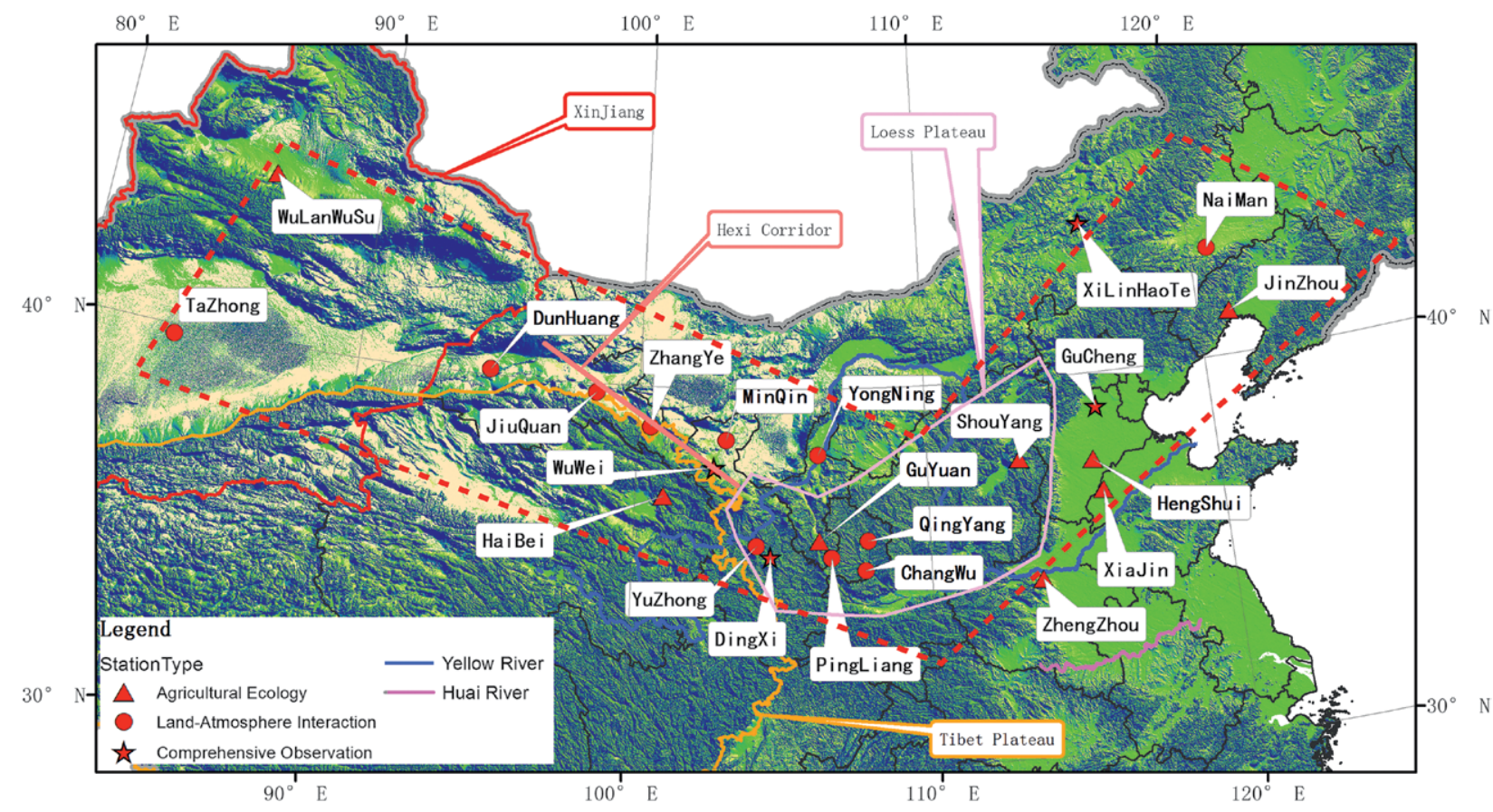

Fıg. I. Field observational experiment station network over northern China.

drought modeling; 4) develop an early-warning system based on multisource observational data and advanced hydrology-climate forecasting models; and 5) establish a regional integrated platform of drought monitoring and warning for information sharing and dissemination. This paper will introduce the observational and experimental system; present preliminary results on key processes for modeling drought disasters, especially over arid and semiarid regions; and demonstrate a prototype of a northern China drought information system.

\section{OBSERVATIONAL AND EXPERIMENTAL} SYSTEM. Experimental design. The observational experiment covers the whole chain of drought development, that is, drought onset-disaster formationdrought recovery. For example, to investigate land-atmosphere interactions during drought, an intensive observation of land surface-boundary layeratmosphere dynamics is required. Drought damages crops by influencing water supply (soil water content), plant water conditions, photosynthetic processes, biomass accumulation, crop growth, and crop yield, among others. Therefore, drought disaster mechanisms are investigated through a series of artificially controlled field experiments and data analyses.

Experimental area and network configuration. Field observation stations are located across northern China, where the climate is arid and semiarid, and the ecological environment is vulnerable. The project designed a V-shape station network layout (Fig. 1), which is mainly made up of many existing meteorological, agricultural, and grassland stations as well as several comprehensive observation stations. The stations are operated collaboratively for continuous and automatic (manual) observational experiments and intensive observations during key periods (Fig. 1). The information on the 23 observational experiment stations is listed in Table 1. In addition, several CMA radiation observation stations were used as auxiliary observations stations. The observations started in June 2015, and simultaneous coupled air soundingintensive observations in multiple experiment regions were carried out in May, July, and September 2017. Preexisting observations were also used for drought analysis.

Experiment components and main instrument. The field experiments consist of three components, namely, land surface processes (Table 2) and atmospheric boundary layer characteristics (Table 3) over arid and semiarid regions, mechanisms for drought disaster onset (Table 4), and the impacts of precipitation on drought duration and recovery (Table 5).

Table 4 shows that the observational elements for the drought mechanism experiment include plant physio-ecological indicators such as the leaf water content, net photosynthetic rate, respiration rate, transpiration rate, stomatal conductance (Gs), 
intercellular $\mathrm{CO}_{2}$ concentration, air temperature of the leaf chamber, photosynthetically active radiation (PAR), leaf area index (LAI), plant height, and dry and fresh yield (crop yield composition). In addition, the artificial soil moisture experiment equipment includes a moisture testing ground with an awning. Table 5 shows the observational elements for investigating the influence of precipitation on drought duration and recovery, where different types (e.g., intensity, durations) of rainfall could be generated artificially and the corresponding water and vegetation responses can be observed.

PRELIMINARY RESULTS ON KEY PROCESSES FOR UNDERSTANDING AND MODELING DROUGHT DISASTERS OVER ARID AND SEMIARID REGIONS. Impact of soil water vapor-heat interactions on soil moisture variability. Droughts usually start as a result of rainfall deficits from the atmosphere, but their impacts are reflected

\begin{tabular}{|c|c|c|}
\hline No. & Station & Information \\
\hline I & Tazhong & $\begin{array}{l}\text { A land-atmosphere interaction and boundary layer } \\
\text { observation station in a desert region in Xinjiang }\end{array}$ \\
\hline 2 & Wulanwusu & \multirow{2}{*}{$\begin{array}{l}\text { Agricultural experiment stations in an oasis region of an } \\
\text { arid region }\end{array}$} \\
\hline 3 & Wuwei & \\
\hline 4 & Zhangye & \multirow{4}{*}{$\begin{array}{l}\text { Arid and Gobi Desert region observations in the Hexi } \\
\text { Corridor }\end{array}$} \\
\hline 5 & Dunhuang & \\
\hline 6 & Jiuquan & \\
\hline 7 & Minqin & \\
\hline 8 & Dingxi & \multirow{8}{*}{$\begin{array}{l}\text { In a semiarid region of the Loess Plateau with farmland } \\
\text { and natural soil surfaces }\end{array}$} \\
\hline 9 & Yuzhong & \\
\hline 10 & Pingliang & \\
\hline II & Guyuan & \\
\hline 12 & Qingyang & \\
\hline 13 & Changwu & \\
\hline 14 & Ansai & \\
\hline 15 & Yongning & \\
\hline 16 & Haibei & $\begin{array}{l}\text { A husbandry meteorological experiment station in the } \\
\text { Qinghai-Tibet Plateau with an underlying alpine grass surface }\end{array}$ \\
\hline 17 & Naiman & $\begin{array}{l}\text { A land-atmosphere interaction and boundary layer } \\
\text { observation station with a desert grassland surface }\end{array}$ \\
\hline 18 & Gucheng & A comprehensive observation station with farmland surface \\
\hline 19 & Hengshui & An ecological monitoring station in a wetland \\
\hline 20 & Xilinhot & A grassland observation station in Inner Mongolia \\
\hline 21 & Xiajin & \multirow{3}{*}{ Featuring agricultural field surfaces in a semihumid region } \\
\hline 22 & Zhengzhou & \\
\hline 23 & Shouyang & \\
\hline
\end{tabular}

in the land surface (e.g., soil moisture deficit and vegetation damage). Therefore, land surface processes are critical for understanding drought impacts, as well as drought disasters. Over arid and semiarid regions, land surface processes are unique as 1) the surface gradient of temperature and moisture is large and soil water is usually transported in the form of water vapor via diffusion in the surface layers, and 2) the surface evaporation rate is closely related to the water vapor diffusion rate. However, most land surface models (LSMs) do not include the soil water vapor diffusion processes. Here, a fully coupled water-heat transport scheme (FCS) was incorporated into the Community Land Model, version 4.5 (CLM4.5), to improve the simulations of soil water and heat transport (Wang and Yang 2018).

Figure 2 shows the simulation results at the Naiman station. In most LSMs (e.g., CLM4.5), only the influences of the soil heat conduction (H_1) and hydraulic potential gradient (W_1) were considered, while the water vapor-induced transport of sensible and latent heat fluxes as well as water vapor fluxes due to temperature gradient and hydraulic potential were ignored. As shown in Fig. 2, CLM4.5 overestimated the surface soil moisture at the Naiman station, while the new scheme with water vapor impacts (FCS) produced a more reasonable simulation as compared with the observations, especially during dry periods. The results suggest that representing soil water vapor-heat interaction processes improves the simulation of soil moisture variability, which is important for drought modeling over arid and semiarid regions.

Effect of intermittent turbulence on atmospheric boundary layer characteristics and energy exchanges. Soil moisture dynamics can affect the overlying atmosphere through turbulence exchanges. Over arid and 
semiarid regions, the effect of intermittency on turbulence is obvious, and it should be considered in the estimation of turbulence fluxes. Turbulent motion in the atmospheric boundary layer can be formed by the accumulation of eddies at different spatiotemporal scales, which can be separated by using the spectrum analysis method. The Hilbert-Huang transform (HHT) can reveal the frequency spectrum of turbulence better than the fast Fourier transform (FFT) and can identify obvious intermittent characteristics of the stable boundary layer. Removing the intermittence of turbulence from the original data can better match similarity of the boundary layer. Observational data from the 20-m-high meteo-

rological tower at the Naiman experiment station in a semiarid region were used, and HHT was applied to analyze the turbulence characteristics of the atmospheric boundary layer with a complicated underlying surface. Figure 3 shows that turbulent motion at night has clear intermittency in the Naiman region (Wei et al. 2016). Two fluctuation periods of 4 and $13 \mathrm{~min}$ exist and correspond to the oscillation periods of the gust and internal gravity waves.

The intermittency of turbulence occurs frequently owing to strong thermodynamic effects. Figure 4 shows the diurnal cycle of turbulent kinetic energy (TKE), shear and sensible heat fluxes averaged during 1-15 April 2011, using the original data [Eddy Covariance (EC); without considering intermittency], and the reconstructed data (reconstructed; with the consideration of intermittency). The turbulent fluxes were overestimated because of nonturbulent motion. In classical eddy covariance systems, the typical averaging period used for turbulence measurements is approximately half an hour. In conditions of intermittent turbulence, such a length may not be well suited to stationarity conditions. Therefore, a new estimation that considers intermittent turbulence would be more reasonable for model development, would reduce the overestimation of the hydrothermal exchange between

TABLE 3. Boundary layer observational elements and instruments.

\begin{tabular}{|l|l|l|}
\hline Category & Observational elements & Experimental methods or equipment \\
\hline \multirow{4}{*}{$\begin{array}{l}\text { Flux observation } \\
\text { (four-floor tower higher than } 20 \mathrm{~m})\end{array}$} & Temperature & Platinum resistor thermometer \\
\cline { 2 - 3 } & Humidity & Humidity-sensitive capacitor \\
\cline { 2 - 3 } & Wind speed & Three-cup anemometer \\
\cline { 2 - 3 } & Wind direction & Wind vane indicator \\
\cline { 2 - 3 } & Ground air pressure & Barometer \\
\hline Profile observation & Wind profile & Wind profile radar, air sounding balloon \\
\cline { 2 - 3 } & Temperature-humidity profile & Air sounding balloon \\
\hline
\end{tabular}


TABLE 4. Observational elements and instruments for drought disaster mechanism experiments.

\begin{tabular}{|c|c|c|}
\hline Category & Observational elements & Experimental methods or equipment \\
\hline \multirow{4}{*}{ Soil characteristics } & Soil moisture $(0-50 \mathrm{~cm})$ & $\begin{array}{l}\text { Automatic soil moisture meter, soil drilling } \\
\text { method }\end{array}$ \\
\hline & Farmland evapotranspiration & Lysimeter, ultrasonic wind-temperature meter \\
\hline & Soil temperature $(0-50 \mathrm{~cm})$ & Platinum resistor thermometer \\
\hline & Soil property & Sample measurement \\
\hline \multirow{10}{*}{$\begin{array}{l}\text { Plant physio-ecological } \\
\text { characteristics }\end{array}$} & $\begin{array}{l}\text { Net photosynthetic rate, respiration rate, } \\
\text { transpiration rate, Gs, intercellular } \mathrm{CO}_{2} \\
\text { concentration, air temperature of leaf chamber, PAR }\end{array}$ & Photosynthesis apparatus (LI-6400XT) \\
\hline & LAI & Leaf area apparatus (LAI-2200) \\
\hline & Density & Manual \\
\hline & Spectrum characteristics & Spectrometer (FiedSpec Pro FR2500) \\
\hline & Dry and fresh yield & Electronic scale, balance \\
\hline & Leaf water content & Drying method \\
\hline & Plant height & Meter scale \\
\hline & Canopy temperature & $\begin{array}{l}\text { Platinum resistor thermometer, infrared } \\
\text { thermometer }\end{array}$ \\
\hline & Chlorophyll & Chlorophyll apparatus (SPAD-502) \\
\hline & Sap flow & Sap flow apparatus (FLOW32) \\
\hline Meteorological conditions & Temperature, humidity, wind speed and direction & Automatic meteorological station \\
\hline $\begin{array}{l}\text { Configuration for artificial } \\
\text { soil moisture experiments }\end{array}$ & $10 \%-100 \%$ of normal soil moisture & Outdoor artificial soil moisture equipment \\
\hline
\end{tabular}

\begin{tabular}{|c|c|c|}
\hline Category & Observational elements & Experimental methods or equipment \\
\hline \multirow{4}{*}{ Rainfall process indicator } & 10- and 30 -min precipitation & Automatic hyetometer \\
\hline & Hourly precipitation & Automatic hyetometer \\
\hline & Precipitation magnitude & Manual \\
\hline & Precipitation phase & Manual \\
\hline \multirow{5}{*}{$\begin{array}{l}\text { Water and soil characteristic } \\
\text { indicators }\end{array}$} & Soil moisture $(0-50 \mathrm{~cm})$ & Automatic soil moisture meter \\
\hline & Soil temperature $(0-50 \mathrm{~cm})$ & Platinum resistor thermometer \\
\hline & Surface runoff & Surface runoff gauge \\
\hline & Soil moisture movement parameters & Laboratory method \\
\hline & Streamflow & Buoy method, hydrometric propeller method \\
\hline \multirow{7}{*}{$\begin{array}{l}\text { Vegetation characteristics } \\
\text { indicators }\end{array}$} & Vegetation type & Manual \\
\hline & Vegetation coverage & Manual \\
\hline & LAI & Leaf area apparatus (LAI-2200) \\
\hline & Spectrum characteristics & Spectrometer (FiedSpec Pro FR2500) \\
\hline & Density & Manual \\
\hline & Leaf water content & Drying method \\
\hline & Height & Meter scale \\
\hline $\begin{array}{l}\text { Meteorological condition } \\
\text { indicators }\end{array}$ & $\begin{array}{l}\text { Temperature, humidity, wind speed, } \\
\text { wind direction }\end{array}$ & Automatic meteorological station \\
\hline Rainfall simulation indicators & $\begin{array}{l}\text { Rainfall duration varying from } 30 \text { to } \\
60 \mathrm{~min} \text {; rainfall intensity varying from } \\
\text { I to } 4 \mathrm{~mm} \mathrm{~min} \text { m }^{-1}\end{array}$ & Field artificial rainfall simulation device \\
\hline
\end{tabular}



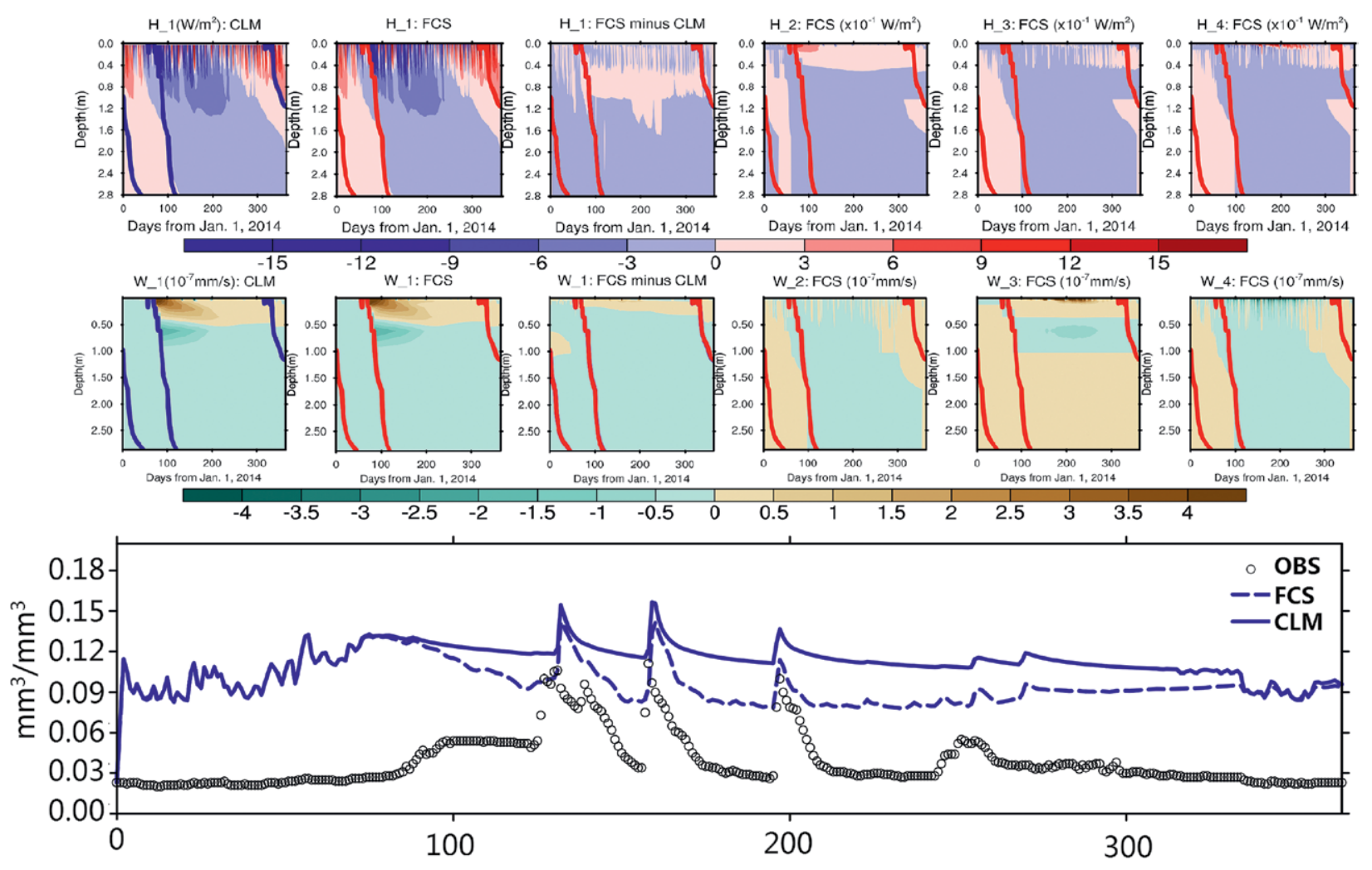

Days from Jan. 1, 2014

Fig. 2. Vertical profiles of four components regarding (top) soil heat fluxes $\left(H \_I, H \_2, H \_3\right.$, and $\left.H \_4 ; W m^{-2}\right)$ and (middle) soil water fluxes $\left(W_{-} l, W_{-} 2, W_{-} 3\right.$, and $\left.W_{-} 4 ; \mathrm{mm} \mathrm{s}^{-1}\right)$ from the new scheme considering water vapor (FCS) and the difference with the CLM. (bottom) Time series of the observed and model-simulated surface soil moisture at a depth of $0.05 \mathrm{~m}$. Components $\mathrm{H}_{-} \mathrm{I}, \mathrm{H}_{-} 2, \mathrm{H}_{-} 3$, and $\mathrm{H}_{-} 4$ represent the soil heat fluxes accounting for conduction, convection of sensible heat with flowing water, transfer of sensible heat via the diffusion of water vapor, and transfer of latent heat via the diffusion of water vapor, respectively. The results are for Naiman station in the northeast part of the study domain. Components $W_{-} I, W_{-} 2, W_{-} 3$, and $W_{-} 4$ represent soil water fluxes due to the hydraulic potential gradient, soil water fluxes due to the temperature gradient, and water vapor fluxes due to the hydraulic potential and temperature gradients, respectively [modified from Wang and Yang (2018)].
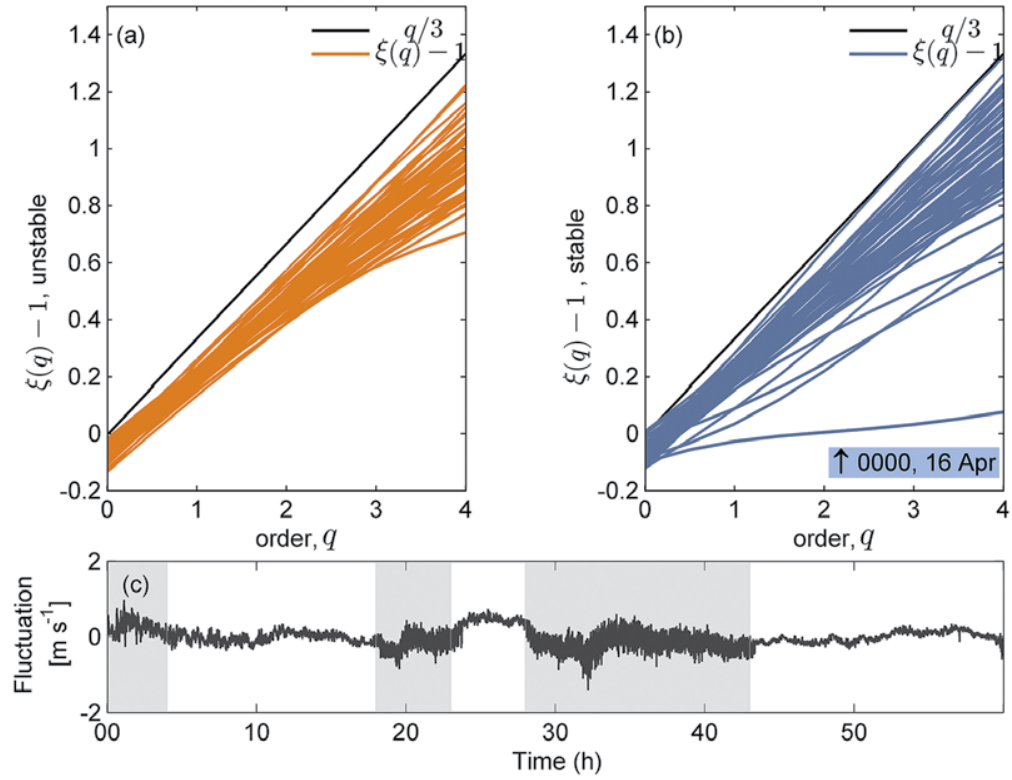

FIG. 3. Intermittent turbulence measured at Naiman station. Change in $\xi(q)$ - I with order $q$ under (a) unstable stratification and (b) stable stratification, where the black straight line represents $\xi(q)-I=q / 3$; (c) the time series of horizontal wind speed pulsation $U$ at 0000-0100 UTC 16 Apr [ $[\xi(q)$ is the Hilbert-based scaling exponent function, and $q$ is the order number (Wei et al. 2016)]. 

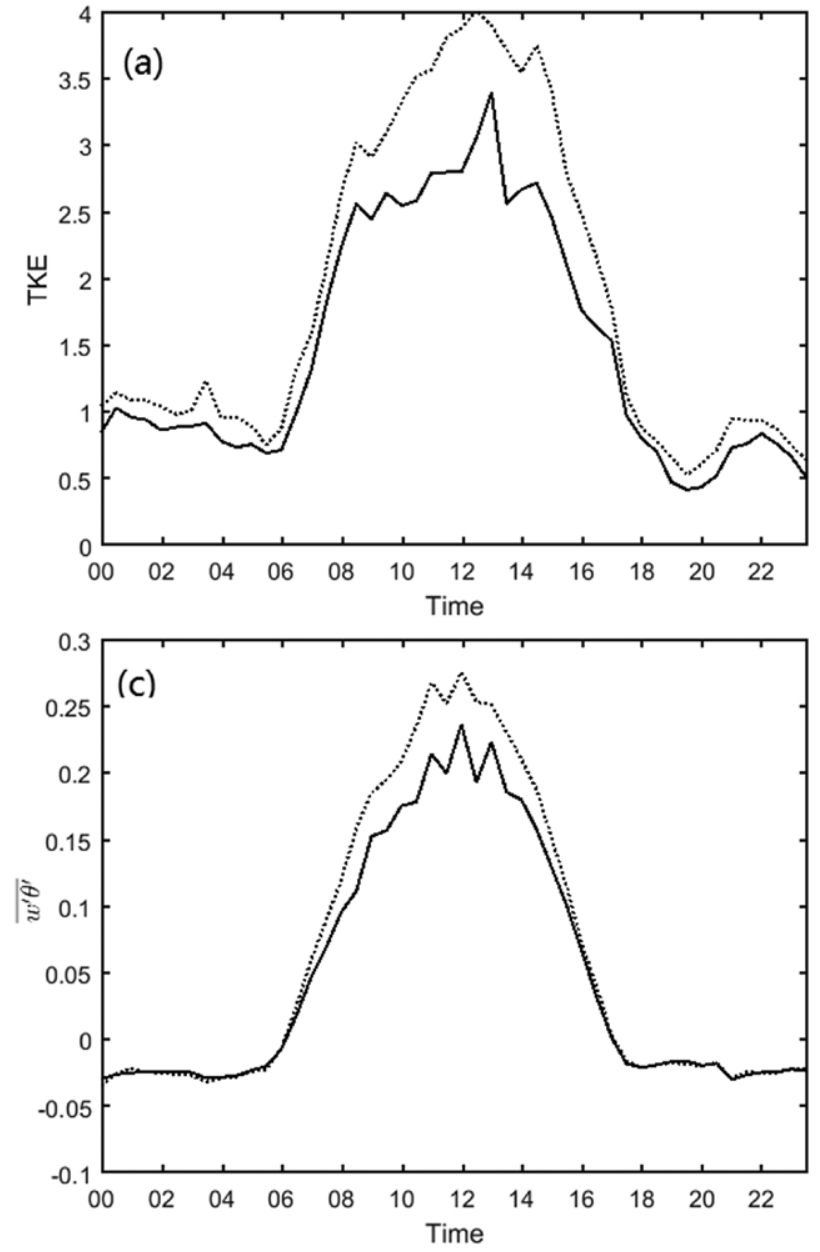

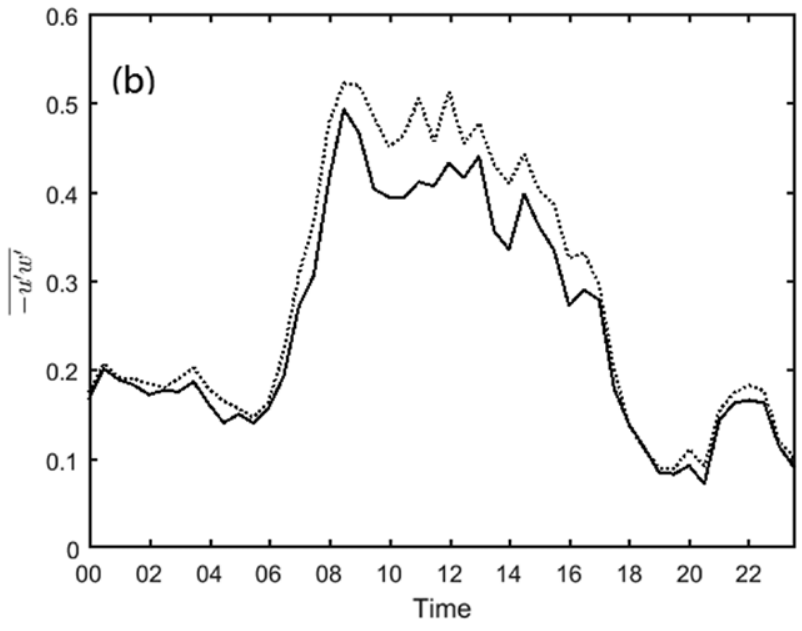

1 -15 Apr, 2011

- Reconstructed

......... EC

FIG. 4. Diurnal cycles of (a) the TKE, (b) the shear, and (c) the sensible heat flux averaged during I-I5 Apr 20 II at Naiman station. The dashed and solid lines are the estimations without and with consideration of the intermittent turbulence, respectively.

the land surface and atmosphere, and would improve drought simulations and predictions (Howell and Mahrt 1997; Vickers and Mahrt 2003).

Albedo-drought feedback over semiarid regions. In addition to soil water vapor-heat interactions and intermittent turbulence, land-use/land-cover change also has a significant influence on the water and energy cycle, especially during drought periods. To model drought-induced changes in albedo and surface energy balance as well as the interaction between albedo and the atmosphere in a semiarid region (i.e., the Loess Plateau) two severe drought cases (2001 and 2005) were selected. The Weather Research and Forecasting (WRF) Model was used for the simulations, with two albedo datasets as the lower boundary layer conditions, namely, the WRF default climatology albedo (CTL simulation) and the time-varying Moderate Resolution Imaging Spectroradiometer (MODIS) albedo (ALB simulation). Figures $5 \mathrm{a}-\mathrm{c}$ show that the albedo reacted to the spring drought in August 2001, especially in the middle and eastern parts of the Loess Plateau, suggesting that the response lag time of the albedo to drought is approximately 3 months over this semiarid region. The response time scale is similar to that over the Murray-Darling Basin in Australia, in which Meng et al. (2014) found that albedo reacted to drought after approximately 3-6 months. Similar changes were found during another drought year of 2005 (Figs. 5d-f). The albedo changes due to drought in 2001 and 2005 were $5.5 \%$ and 3\%, respectively.

Changes in albedo can affect the surface energy balance, thus affecting the atmospheric state and subsequent precipitation. To investigate the influence of drought-related albedo change on the subsequent summer precipitation over the Loess Plateau, we used a convective triggering potential and low-level humidity index (CTP-HI $\left.{ }_{\text {low }}\right)$ framework developed by Findell and Eltahir (2003) to 

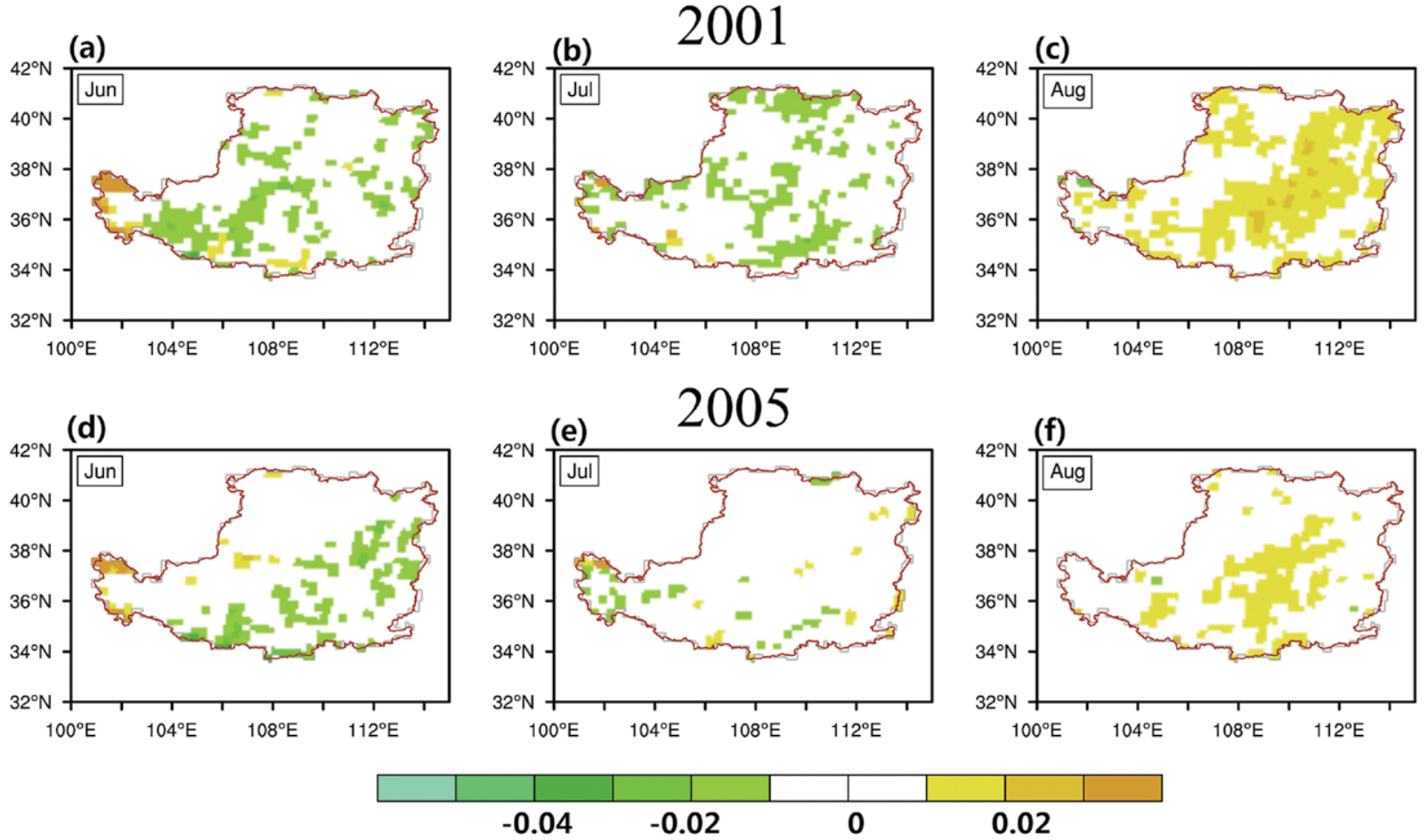

(g)
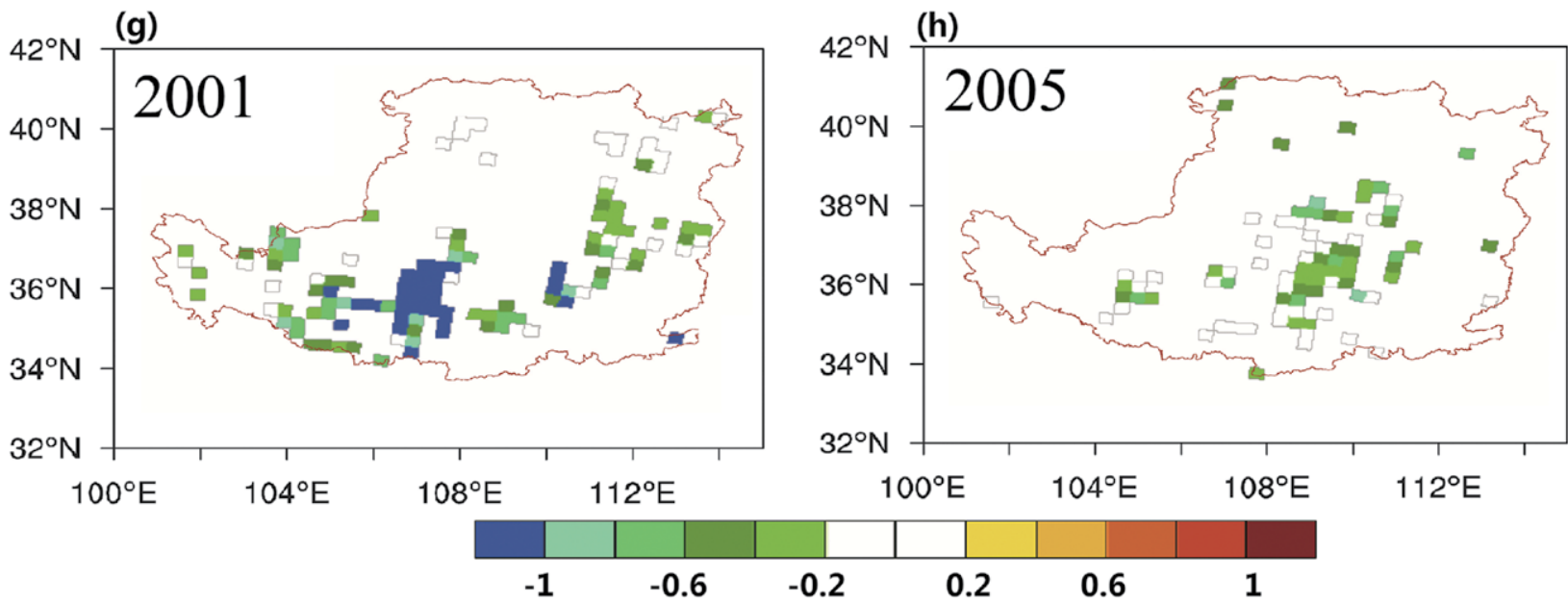

FIG. 5. (a)-(f) Differences in the monthly albedo variations during summer between the CTL and ALB simulations in $200 \mathrm{I}$ and 2005. (g),(h) Regional climate model (WRF)-simulated convective precipitation changes due to albedo variations resulting from drought during the summers of $200 \mathrm{I}$ and 2005 , respectively.

calculate the albedo-induced convective precipitation changes. The convective triggering potential (CTP) represents a measure of the temperature lapse rate taken between 100 and $300 \mathrm{~m}$ above the land surface (i.e., approximately 750 and $550 \mathrm{hPa}$, respectively, assuming a surface pressure of $850 \mathrm{hPa}$ over the Loess Plateau) and provides insight into the boundary layer response to surface flux development. The low-level humidity index $\left(\mathrm{HI}_{\text {low }}\right)$ was defined by Findell and Eltahir (2003) and Findell et al. (2011) as the sum of the dewpoint depressions 50 and $100 \mathrm{~m}$ above the ground surface. Figures $5 \mathrm{~g}$ and $5 \mathrm{~h}$ show that the albedo changes affected convective precipitation with a larger influence in 2001 due to a larger albedo change. On average, the precipitation changes in the affected regions are $27 \%$ and $11 \%$ for 2001 and 2005 , respectively, leading to a positive feedback on the summer drought.

Influence of drought stress on the physiological and ecological characteristics of different crops. The DroughtEX_China project not only focuses on the physical mechanisms of drought (e.g., soil water vapor-heat interaction, intermittent turbulence, 
and the drought-albedo feedback introduced above) but also attempts to investigate the mechanisms for drought disasters. Understanding the effects of drought stress on the physiological and ecological characteristics of crops is an important step toward drought impact analysis and drought adaptation. In this project, a set of observational experiments were conducted with measurements of physio-biochemical indicators of wheat, corn, potato, and cotton under irrigation and drought conditions. The changes in
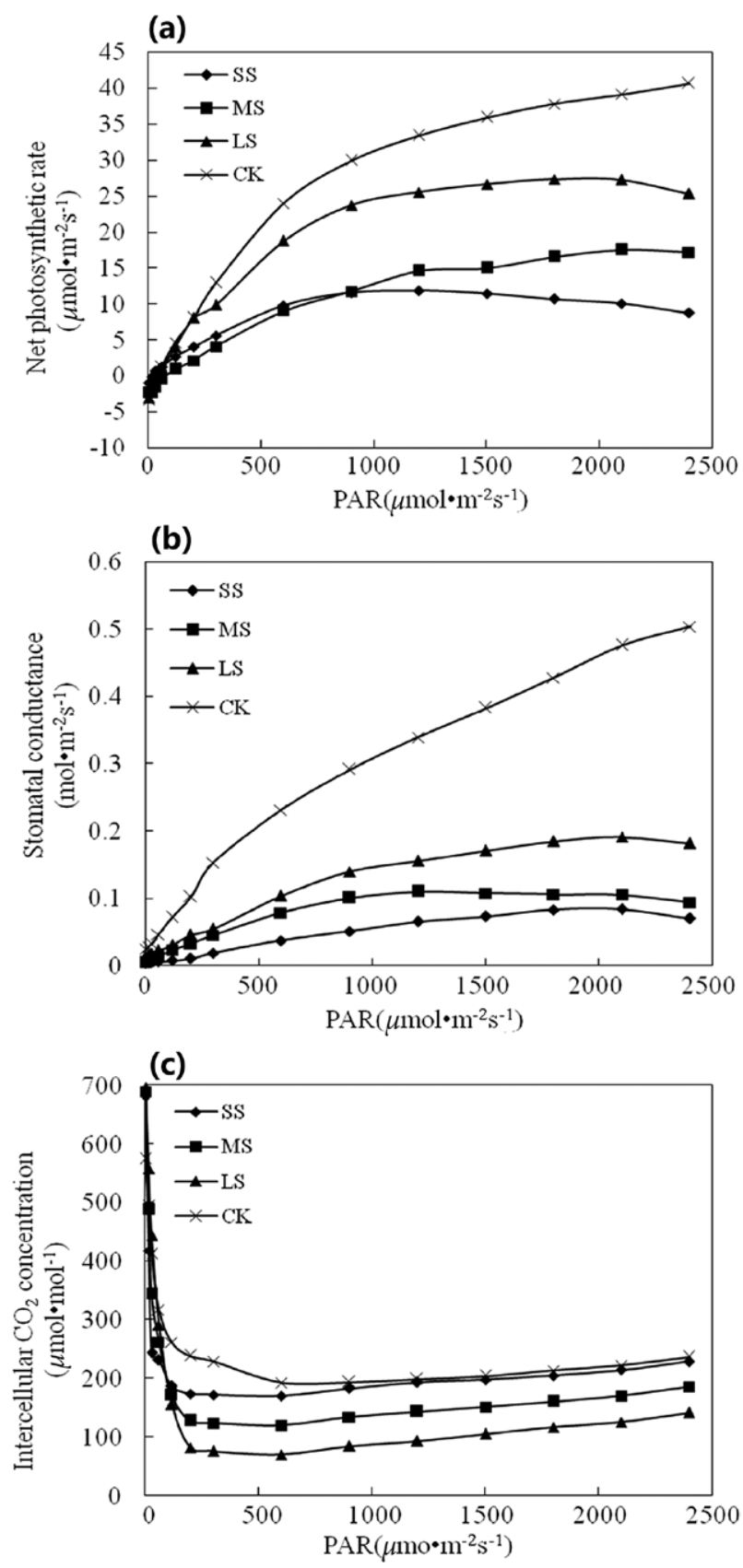

FIG. 6. Reaction curves of spring corn leaf photosynthesis with respect to PAR under different drought stresses. physio-biochemical indicators under different treatments could reflect the crop adaptation to drought. The drought stress mainly caused the degradation of wheat tillering, further resulting in a significant difference in wheat density compared with that under normal irrigation conditions (4 times the irrigation amount for the entire growing period; $105 \mathrm{~kg} \mathrm{~m}^{-2}$ each time). Under drought conditions, the LAI for different crops (corn and cotton) was lower than that with sufficient irrigation. Persistent soil drought greatly suppressed potato growth in terms of height and size. Droughts could lead to a remarkable decrease in the crop yield, which could be exacerbated when the drought persists.

Drought stress led to a decrease in chlorophyll concentration, thus resulting in significant differences in the photosynthesis rate and transpiration rate; such reduction would be amplified if the drought intensified. For example, the net photosynthetic rates (Pn) of spring corn leaves had consistent and sensitive reactions to PAR under different drought conditions, showing a tendency to stabilize or decrease after a sharp increase (Fig. 6a). The value of Gs increased rapidly as PAR increased, especially for those without drought stress (Fig. 6b), and the intercellular $\mathrm{CO}_{2}$ concentration $(\mathrm{Ci})$ decreased significantly as PAR increased and increased slightly when PAR was larger than a certain threshold (Fig. 6c). Under the same PAR, Pn and Gs for spring corn leaves were generally as follows: normal irrigation $(\mathrm{CK}) \geq$ light drought stress (LS) $\geq$ medium drought stress (MS) $\geq$ severe drought stress (SS) (Figs. 6a,b). Therefore, drought stress increased the resistance of the stoma and decreased $\mathrm{CO}_{2}$ absorption and photosynthesis (Jiang et al. 2015).

The observational experiment suggested that leaf water content is a good indicator for the water potential of plants under stress conditions as well as for the water usage of plants (Fig. 7). If there was a drought during the key growth period of corn, the leaf water content decreased gradually with the intensification of drought, whereas the relative saturation deficit and the water absorption rate increased gradually. Meanwhile, the crop water shortage increased, and the drought adaptation capability weakened dramatically. In arid and semiarid regions, the crop water stress index (CWSI), which is defined as CWSI $=1-\mathrm{LE} / \mathrm{EP}$, where LE and EP indicate the actual and potential evapotranspiration, respectively (Shen and Tian 1998), ranged from 0.242 to 0.390 for corn and from 0.305 to 0.342 for spring wheat. In this observational experiment, the CWSI was relatively low, which suggests that the crop's adaptation capability increased. 
A PROTOTYPE OF A NORTHERN CHINA DROUGHT INFORMATION SYSTEM.

Multimodel ensemble drought forecasting. Based on the understanding of the key processes from soil moisture-vapor movement to intermittent turbulence and from albedo-drought feedback to drought's ecological impact, a better land-atmosphere coupled model for simulating water and energy cycle as well as drought disasters is expected over northern China. However, in order to make a skillful drought prediction at long leads, land-atmosphere coupled models should be combined with oceanic models that resolve large-scale climate variability. To demonstrate the possibility of establishing a drought early-warning system for northern China, we collected six North American Multimodel Ensemble (NMME; Kirtman et al. 2014) ocean-atmosphere coupled models with complete soil moisture hindcast datasets for the period 1982-2010 and assessed their forecasting skill through a comparison with the European Centre for Medium-Range Weather Forecasts (ECMWF) interim reanalysis (ERA-Interim) soil moisture data. To enable comparisons among different models, the soil moisture was first standardized. The forecasting skill in terms of anomaly correlation (AC) can be very high without such a standardization procedure (not shown), suggesting strong land surface heterogeneity over northern China. Figure 8 shows the AC of the seasonal mean soil moisture for winter [December-February (DJF)] and summer [June-August (JJA)], with the forecasting skill in winter generally being higher than that in summer. During winter, two Canadian models [Third Generation and Fourth Generation Canadian Coupled Global Climate Model (CanCM3 and CanCM4)] and National Centers for Environmental Prediction's (NCEP) Climate Forecast System, version 2 (CFSv2), exhibited high skill for the central and eastern parts of northern China, with $\mathrm{AC}$ values of 0.3-0.5. Two National Center for Atmospheric Research (NCAR) models did not display good forecasting skill, which might be partly due to the absence of land surface initialization when performing seasonal hindcast experiments. The forecasting skill of the simple multimodel arithmetic mean (NMME1) falls between that of the best and worst models except for the Song-Huajiang River basin in northeastern China. By using an optimization procedure (Zhou et al. 1997; Yuan et al. 2012; Yao and Yuan 2018) to assign different weights to different models that have variable skill, the resulting NMME2 forecasting skill was substantially improved for all of northern China. Note that NMME2 involved an estimation without cross validation; that is, NMME2 is the potential upper limit of the forecasting skill. A comparison between the simple ensemble mean (NMME1) and superensemble mean (NMME2) showed that there is room for further improvement, especially for the summer season where the low skill in individual models resulted in a low skill in the simple ensemble mean (NMME1).

Similar to other NMME studies (Mo and Lettenmaier 2014; Thober et al. 2015; Yuan et al.

(a)

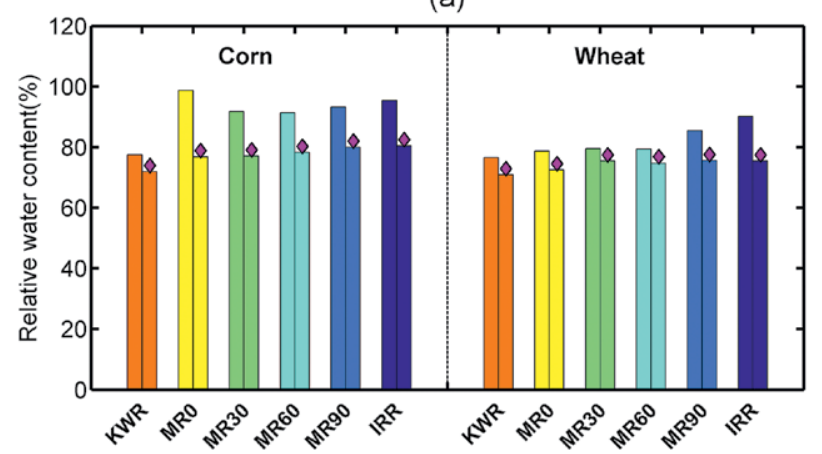

(b)

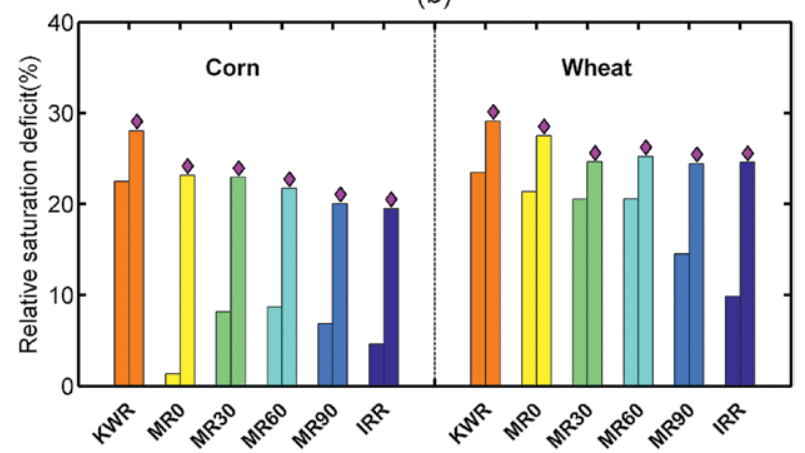

(c)

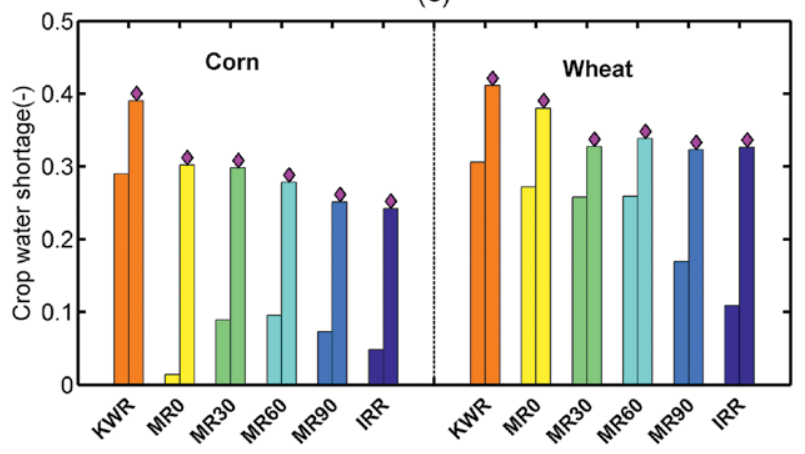

Fig. 7. Measurement of main drought resistance indicators for dryland crops under artificial rainfall (drought stress) conditions during 2015-16. The bar plots with (without) pink diamonds represent the results for severe (moderate) drought conditions. The rainfall conditions for the observational experiments are as follows: that without any natural or artificial rainfall (KWR), natural rainfall only (MRO), and natural rainfall plus 30 (MR30), 60 (MR60), 90 (MR90), and $150 \mathrm{~mm}$ of artificial rainfall (IRR). Here, $150 \mathrm{~mm}$ of artificial rainfall is considered a sufficient irrigation condition. 
2015; Sikder et al. 2016), these NMME climate forecast models did show some skill and may be useful in hydrological forecasting. Therefore, the meteorological hindcasts were downscaled and bias corrected to drive a well-calibrated land surface hydrological model [Variable Infiltration Capacity (VIC)] to provide hydrological drought forecasting for the Yellow River basin in northern China, using an experimental
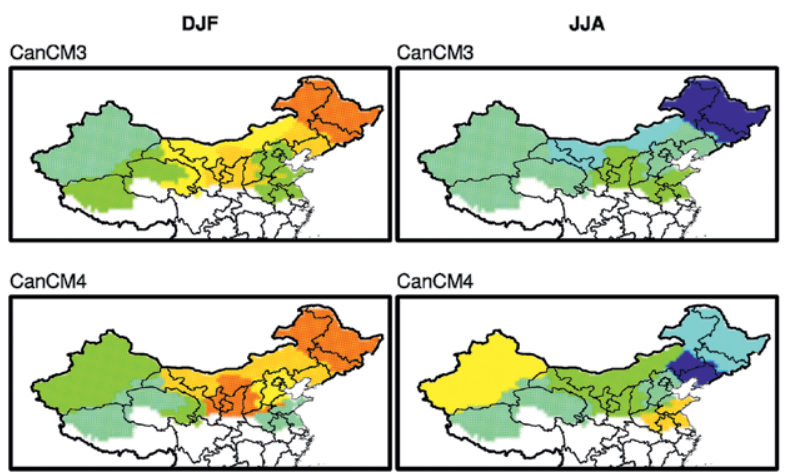

GFDL-CM2p1

GFDL-CM2p1
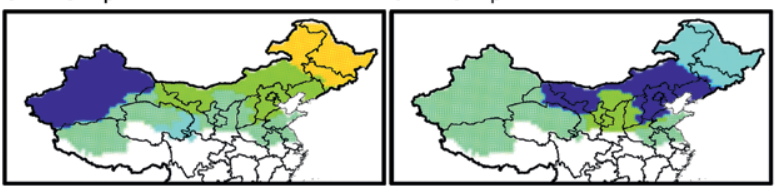

CESM1

CESM1
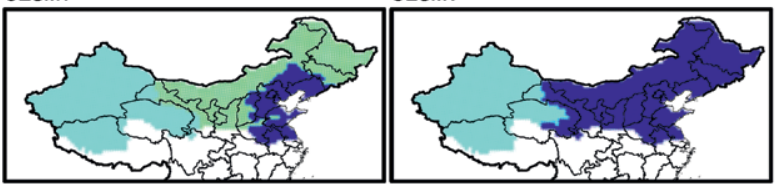

CCSM3

CCSM3

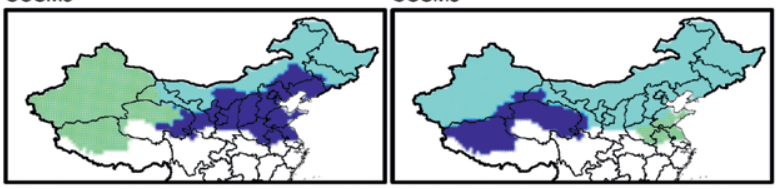

CFSv2

CFSv2

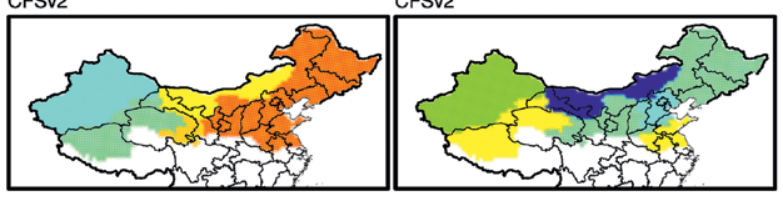

NMME1

NMME1

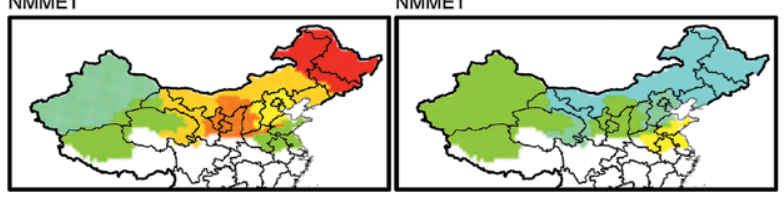

NMME2 NMME2

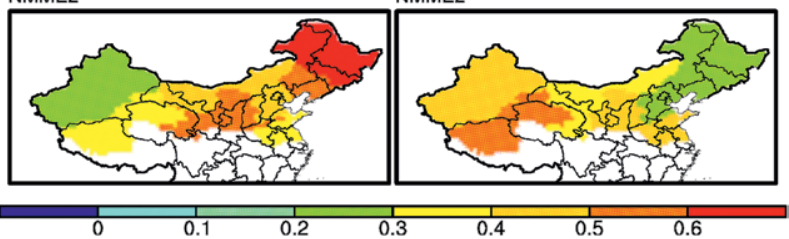

forecasting system developed by Yuan et al. (2016). A drought case of 2002 was selected to verify the ensemble forecasting of a hydrological drought index, that is, the standardized streamflow index (SSI). Figure 9 shows the ensemble forecasts started from February and June of 2002 for five selected gauges from the upper to lower reaches of the Yellow River basin. In the February SSI forecast, the climatological forecast method [ensemble streamflow prediction (ESP)/VIC] had some positive forecasting skill; however, the method entirely missed the hydrological drought in the June forecast with the ensemble-mean SSIs (blue lines in the left panels of Fig. 9) being close to zero and larger than the drought threshold line of -0.8 . Using the climate-model-based approach (NMME/ VIC), a number of ensembles could capture the hydrological drought conditions during summer, with the ensemble-mean SSIs (blue lines in the right panels of Fig. 9) being closer to the reference (black line). This demonstration is just an example showing the potential of the experimental system in hydrological drought forecasting, and more comprehensive evaluations can be found in Yuan et al. (2017).

Integrated multisource drought information platform. This project integrates and manages data via a shared platform - the Information Integration and Data Sharing Platform of China Drought Information. This project applied a relational database management system (RDBMS) to integrate structured and nonstructured meteorological metadata and all the observational experimental data and products collected by DroughtEX_China and to classify the information and manage the documents in accordance with international standards. With the help of the basic information technology resource from the CMA Cloud Platform, an open data-sharing platform was established utilizing distributed database technology

Fig. 8. AC of the predicted seasonal-mean standardized soil moisture over river basins in northern China at the lead- 0 season. The results were calculated using (left) hindcasts starting in Dec during 1982-2010, and (right) hindcasts starting in Jun. The soil moisture predictions were directly generated by six NMME models, including CanCM3; CanCM4; Geophysical Fluid Dynamics Laboratory Climate Model, version 2.I (GFDL CM2.I); Community Earth System Model, version I (CESMI); Community Climate System Model, version 3 (CCSM3); and CFSv2. NMMEI is the simple arithmetic mean of standardized soil moisture from the above six models, and NMME2 is the superensemble mean of six models using an optimization method [see Yao and Yuan (2018) for details]. 
and a service-oriented architecture system to provide data search and download services. Figure 10 shows the structure of the information-sharing platform. The platform will ensure that the experimental data and products are conveniently utilized by the drought community. After completion of this project, the DroughtEX_ China data will be posted on the China Meteorological Data Service Center website (http://data.cma.cn /en) for public access with a proper registration.

\section{SUMMARY AND CONCLUSIONS.}

DroughtEX_China, a scientific research program focusing on the mechanisms of drought disasters, is aimed at establishing a comprehensive observational experimental system for drought research in arid and semiarid regions in northern China based on existing meteorological, agricultural, and ecological stations and by carrying out interdisciplinary, comprehensive, and systematic drought observations and scientific experiments via regular and intensive observations as well as artificially controlled experiments. Understanding drought disaster mechanisms and improving the simulations of drought-related processes will facilitate the development of a drought early-warning capacity. Since the implementation of the project in 2015, the following progress has been made:

1) A comprehensive $V$-shape drought observational experiment system for understanding drought disaster processes and mechanisms was constructed for northern China, and continuous, automatic (artificial) observational experiments were performed. Intensive observations were carried out during key periods.
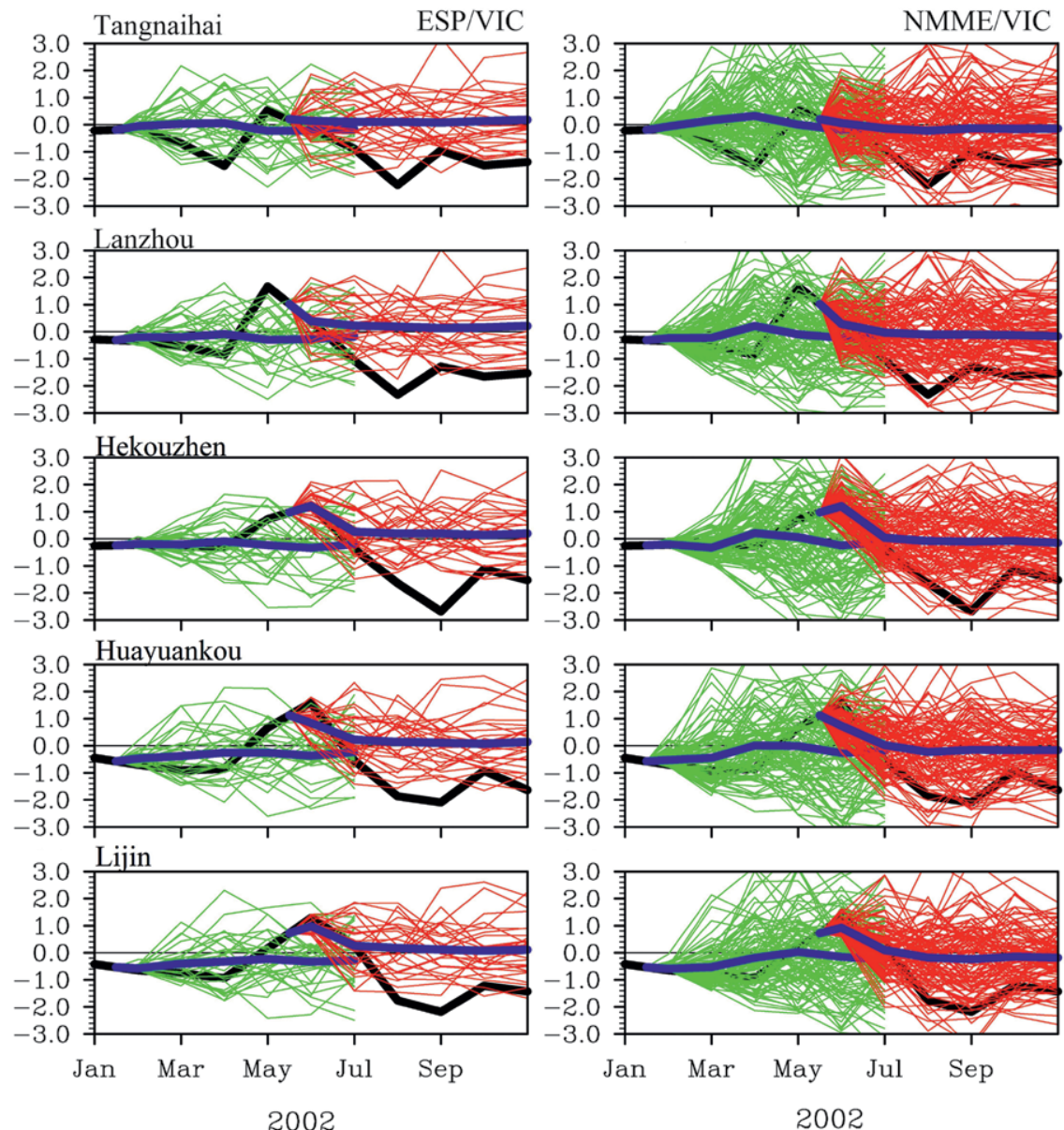

Fig. 9. Seasonal ensemble hindcasts of 2002 Yellow River hydrological droughts from upstream to downstream gauges, produced using a climatology method (ESP/VIC) and a climate-model-based approach (NMME/VIC). The vertical axes are the SSI, where SSI < $\mathbf{- 0 . 8}$ represents a hydrological drought condition. The solid black lines represent the SSI simulated with the hydrological model VIC with observed meteorological forcings; the green and red lines represent the individual ensemble members from the hindcasts starting from the beginning of Feb and Jun, respectively; and the blue lines denote the ensemble means of the hindcasts.

2) Observational datasets were used to investigate soil water vapor-heat interactions and improve soil moisture simulations to study the effects of intermittent turbulence and drought-albedo feedback on boundary layer water-energy exchanges and convection over arid and semiarid regions and to understand the transition processes between the stomatal and nonstomatal control of crop photosynthesis with increasing drought severity.

3) A prototype drought information system for northern China was developed, including a multimodel ensemble drought forecast system that provided skillful seasonal predictions of agricultural and hydrological droughts over northern China 


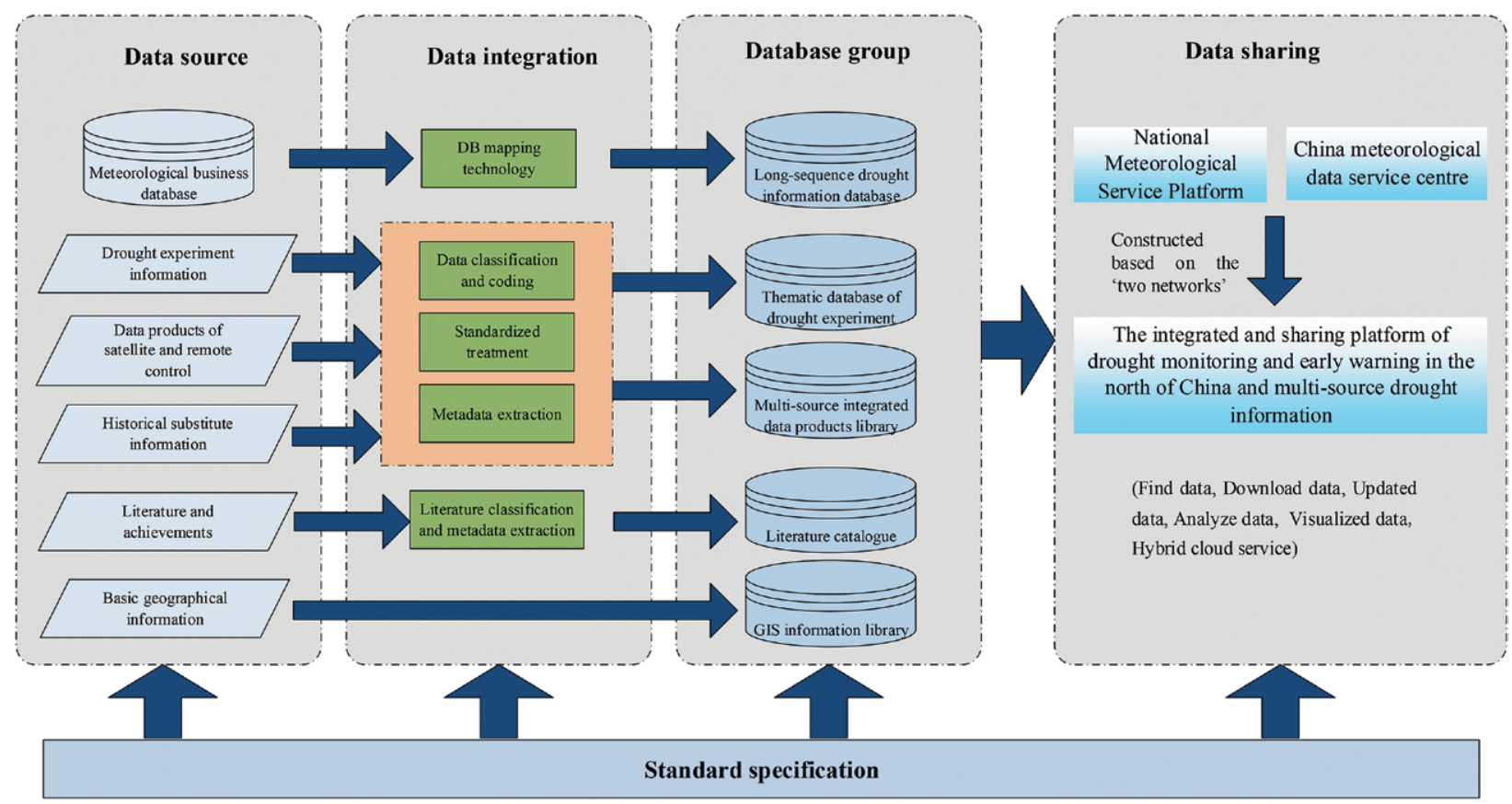

FIG. I0. Diagram of the drought information-sharing platform.

and a multisource drought information platform that integrated long-term station observation data and products, drought scientific observations, and an experimental database. The information system includes standardized data products and process flows and a drought-related informationintegrating and data-sharing platform for northern China, which represent important contributions to the global drought information system (GDIS).

ACKNOWLEDGMENTS. This work is sponsored by a special and significant research project for public benefit (meteorology branch), DroughtEX_China (GYHY201506001), of the Ministry of Science and Technology, and a foundation project "Study on the Relevance of Land-Atmosphere Coupling Systems between the Tibetan Plateau and Desert Regions in the North of TP and its Impacts on the Drought in Northern China (91837209)" of the National Natural Science Foundation of China. Further, thanks to all the experts and scientific researchers who have made great contributions to the completion of this paper.

\section{REFERENCES}

Findell, K. L., and E. A. B. Eltahir, 2003: Atmospheric controls on soil moisture-boundary layer interactions. Part I: Framework development. J. Hydrometeor., 4, 552-569, https://doi.org/10.1175/15257541(2003)004<0552:ACOSML>2.0.CO;2.
— , P. Gentine, B. R. Lintner, and C. Kerr, 2011: Probability of afternoon precipitation in eastern United States and Mexico enhanced by high evaporation. Nat. Geosci., 4, 434-439, https://doi.org/10.1038 /ngeo1174.

Hoerling, M., J. Eischeid, A. Kumar, R. Leung, A. Mariotti, K. Mo, S. Schubert, and R. Seager, 2014: Causes and predictability of the 2012 Great Plains drought. Bull. Amer. Meteor. Soc., 95, 269-282, https://doi.org/10.1175/BAMS-D-13-00055.1.

Howell, J. F., and L. Mahrt, 1997: Multiresolution flux decomposition. Bound.-Layer Meteor., 83, 117-137, https://doi.org/10.1023/A:1000210427798.

Huang, J., M. Ji, Y. Xie, S. Wang, Y. He, and J. Ran, 2016a: Global semi-arid climate change over last 60 years. Climate Dyn., 46, 1131-1150, https://doi.org/10.1007 /s00382-015-2636-8.

—, H. Yu, X. Guan, G. Wang, and R. Guo, 2016b: Accelerated dryland expansion under climate change. Nat. Climate Change, 6, 166-171, https://doi .org/10.1038/nclimate2837.

Jiang, J. F., and Coauthors, 2015: Response of spring maize leaves to light intensity and $\mathrm{CO}_{2}$ concentration under drought stress. Chin. Agric. Sci. Bull., 31, 43-48.

Kirtman, B., and Coauthors, 2014: The North American Multimodel Ensemble: Phase-1 seasonal-to-interannual prediction; phase-2 toward developing intraseasonal prediction. Bull. Amer. Meteor. Soc., 95, 585601, https://doi.org/10.1175/BAMS-D-12-00050.1. 
Meng, X. H., J. P. Evans, and M. F. McCabe, 2014: The influence of inter-annually varying albedo on regional climate and drought. Climate Dyn., 42, 787-803, https://doi.org/10.1007/s00382-013-1790-0.

Mo, K. C., and D. P. Lettenmaier, 2014: Hydrologic prediction over the conterminous United States using the National Multi-Model Ensemble. J. Hydrometeor., 15, 1457-1472, https://doi.org/10.1175 /JHM-D-13-0197.1.

Schubert, S. D., and Coauthors, 2009: A U.S. CLIVAR project to assess and compare the responses of global climate models to drought-related SST forcing patterns: Overview and results. J. Climate, 22, 5251-5272, https://doi.org/10.1175/2009JCLI3060.1.

Shen, G. R., and G. L. Tian, 1998: Drought monitoring with crop water stress index (in Chinese). Ganhan Diqu Nongye Yanjiu, 16, 123-128.

Sikder, S., X. Chen, F. Hossain, J. Roberts, F. Robertson, C. Shum, and F. Turk, 2016: Are general circulation models ready for operational streamflow forecasting for water management in the Ganges and Brahmaputra River basins? J. Hydrometeor., 17, 195-210, https:// doi.org/10.1175/JHM-D-14-0099.1.

Thober, S., R. Kumar, J. Sheffield, J. Mai, D. Schäfer, and L. Samaniego, 2015: Seasonal soil moisture drought prediction over Europe using the North American Multi-Model Ensemble (NMME). J. Hydrometeor., 16, 2329-2344, https://doi.org/10.1175 /JHM-D-15-0053.1.

Trenberth, K. E., A. Dai, G. van der Schrier, P. Jones, J. Barichivich, K. R. Briffa, and J. Sheffield, 2014: Global warming and changes in drought. Nat. Climate Change, 4, 17-22, https://doi.org/10.1038/nclimate2067.

Vickers, D., and L. Mahrt, 2003: The cospectral gap and turbulent flux calculations. J. Atmos. Oceanic Technol., 20, 660-672, https://doi.org/10.1175/1520 -0426(2003)20<660:TCGATF>2.0.CO;2.

Wang, C., and K. Yang, 2018: A new scheme for considering soil water-heat transport coupling based on Community Land Model: Model description and preliminary validation. J. Adv. Model. Earth Syst., 10, 927-950, https://doi.org/10.1002/2017 MS001148.
Wang, S., X. Yuan, and Y. Li, 2017: Does a strong El Niño imply a higher predictability of extreme drought? Sci. Rep., 7, 40741, https://doi.org/10.1038/srep40741.

Wei, W., F. G. Schmitt, Y. X. Huang, and H. S. Zhang, 2016: The analyses of turbulence characteristics in the atmospheric surface layer using arbitrary-order Hilbert spectra. Bound.-Layer Meteor., 159, 391-406, https://doi.org/10.1007/s10546-015-0122-9.

Yao, M., and X. Yuan, 2018: Superensemble seasonal forecasting of soil moisture by NMME. Int. J. Climatol., 38, 2565-2574, https://doi.org/10.1002/joc .5436 .

Yuan, X., X.-Z. Liang, and E. F. Wood, 2012: WRF ensemble downscaling seasonal forecasts of China winter precipitation during 1982-2008. Climate Dyn., 39, 2041-2058, https://doi.org/10.1007/s00382 $-011-1241-8$.

— , J. K. Roundy, E. F. Wood, and J. Sheffield, 2015: Seasonal forecasting of global hydrologic extremes: System development and evaluation over GEWEX basins. Bull. Amer. Meteor. Soc., 96, 1895-1912, https://doi.org/10.1175/BAMS-D-14-00003.1.

_-, F. Ma, L. Wang, Z. Zheng, Z. Ma, A. Ye, and S. Peng, 2016: An experimental seasonal hydrological forecasting system over the Yellow River basin-Part 1: Understanding the role of initial hydrological conditions. Hydrol. Earth Syst. Sci., 20, 2437-2451, https://doi.org/10.5194/hess-20-2437-2016.

—, M. Zhang, L. Wang, and T. Zhou, 2017: Understanding and seasonal forecasting of hydrological drought in the Anthropocene. Hydrol. Earth Syst. Sci., 21, 5477-5492, https://doi.org/10.5194/hess-21 $-5477-2017$.

Zhang, L., and T. Zhou, 2015: Drought over East Asia: A review. J. Climate, 28, 3375-3399, https://doi .org/10.1175/JCLI-D-14-00259.1.

Zhou, J. L., A. L. Tits, and C. T. Lawrence, 1997: User's guide for FFSQP version 3.7: A FORTRAN code for solving constrained nonlinear (minimax) optimization problems, generating iterates satisfying all inequality and linear constraint. University of Maryland Institute for Systems Research Tech. Rep. SRC-TR-92-107r5, 44 pp. 


\section{AMS BOOKS RESEARCH APPLICATIONS HISTORY}

CLIMATE

The Thinking Person's Guide to Climate Change ROBERT HENSON

This fully updated and expanded revision of The Rough Guide to Climate Change combines years of data with recent research. It is the most comprehensive acknowledging controversies but standing strong in its stance that the climate is changing-and something needs to be done.

(c) 2014, PAPERBACK, 520 PAGES,

ISBN: 978-1-935704-73-7

LIST \$30 MEMBER \$20 overview of climate science,

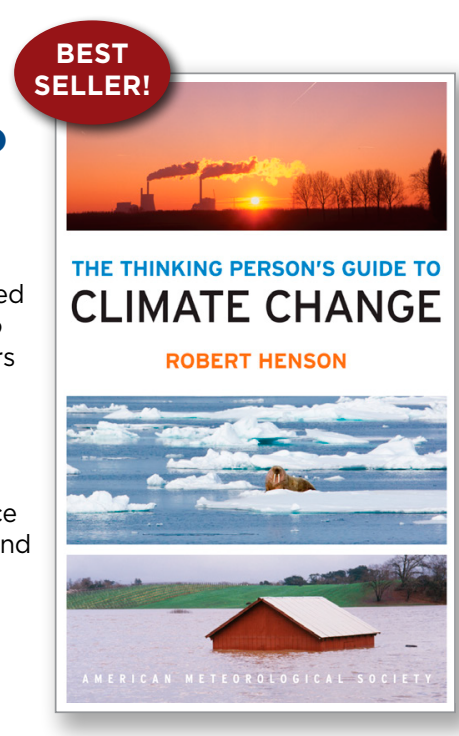

\section{Climate Conundrums:} What the Climate Debate Reveals about Us

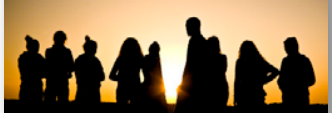

WILLIAM B. GAIL

This is a journey through how we think, individually and collectively, about humanity's relationship with nature, and more. Can we make nature better? Could science and religion reconcile? Gail's insights on such issues help us better understand who we are and find a way forward.

(c) 2014, PAPERBACK, 240 PAGES, ISBN: 978-1-935704-74-4 LIST \$30 MEMBER \$20
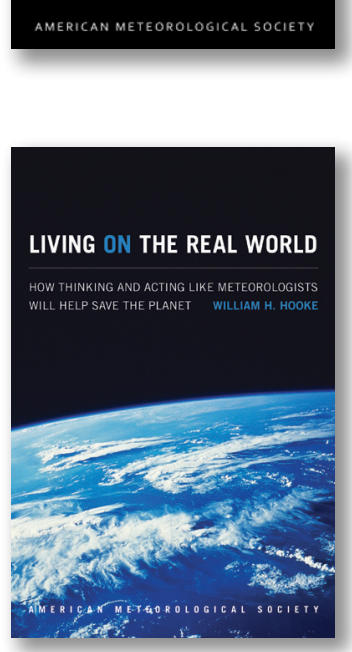

\section{Living on the}

\section{Real World:}

How Thinking and Acting Like Meteorologists

Will Help Save the Planet WILLIAM H. HOOKE

Meteorologists focus on small bits of information while using frequent collaboration to make decisions. With climate change a reality, William $\mathrm{H}$. Hooke suggests we look to the way meteorologists operate as a model for how we can solve the 21st century's most urgent environmental problems.

(c) 2014, PAPERBACK, 272 PAGES, ISBN 978-1-935704-56-0 LIST \$30 MEMBER \$22

\section{Synoptic-Dynamic Meteorology Lab Manual:}

Visual Exercises to Complement Midlatitude Synoptic Meteorology

\section{GARY LACKMANN, BRIAN E. MAPES, AND KEVIN R. TYLE}

These labs link theoretical concepts with groundbreaking visualization to elucidate concepts taught in the award-winning companion textbook by Gary Lackmann, Midlatitude Synoptic Meteorology.

(c) 2017, PAPERBACK, 126 PAGES, ISBN 978-1-878220-26-4 LIST \$80 MEMBER \$60 STUDENT \$50

\section{GUIDES}

\section{An Observer's Guide to Clouds}

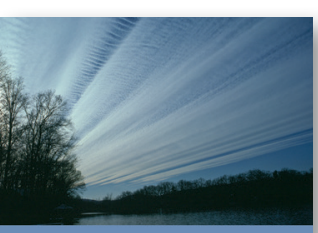

AN OBSERVER'S GUIDE CLOUDS AND WEATHER A NORTHEASTERN PRIMER ON PREDICTION

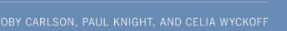
and Weather:

A Northeastern Primer on Prediction

TOBY CARLSON, PAUL KNIGHT, AND CELIA WYCKOFF

With help from Penn State experts, start at the beginning and go deep. This primer, intended for both serious enthusiasts and new meteorology students, will leave you with both refined observation skills and an understanding of the complex science behind the weather: the ingredients for making reliable predictions of your own. It connects fundamental meteorological concepts with the processes that shape

weather patterns, and will make an expert of any dedicated reader.

(c) 2014, PAPERBACK, 210 PAGES,

ISBN: 978-1-935704-58-4 LIST \$30 MEMBER \$20

\section{Eloquent Science:}

A Practical Guide to Becoming a Better Writer, Speaker, and Atmospheric Scientist DAVID M. SCHULTZ

The ultimate communications manual for undergraduate and graduate students as well as researchers in the atmospheric sciences and their intersecting disciplines.

(C) 2009, PAPERBACK, 440 PAGES,

ISBN 978-1-878220-91-2

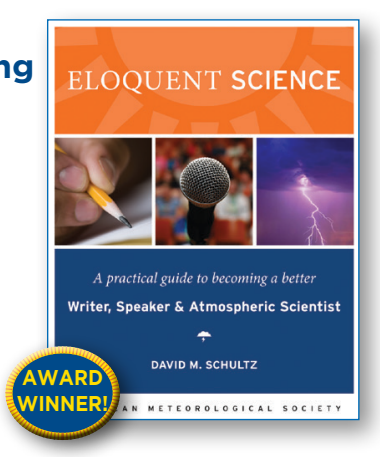

LIST \$45 MEMBER \$30 


\section{SHIPPING + DISCOUNTS AT BOOKSTORE.AMETSOC.ORG}

NEW

Verner Suomi: The Life and Work of the Founder of Satellite Meteorology

JOHN M. LEWIS WITH JEAN M. PHILLIPS, W. PAUL MENZEL, THOMAS H. VONDER HAAR, HANS MOOSMÜLLER, FREDERICK B. HOUSE, AND MATTHEW G. FEARON

Born in a Minnesotan mining town, Suomi would spend his best years next door in Wisconsin, but not before seeing the whole world-from space, that is. This is the story of the scientist, inventor, and teacher who founded satellite meteorology, written by

members of the communities that grew up around his groundbreaking work.

LIST \$3O MEMBER \$20

(c) 2016, PAPERBACK, 240 PAGES, ISBN: 978-1-944970-22-2

\section{Weather in the Courtroom: Memoirs from a Career iForensic Meteorology}
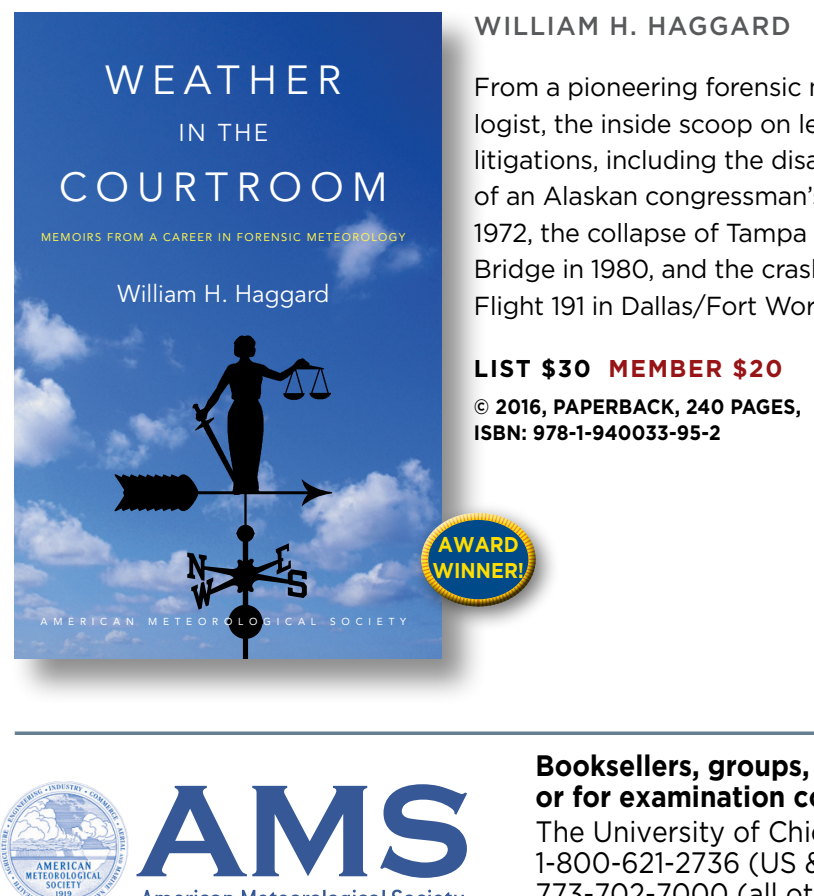

American Meteorological Society

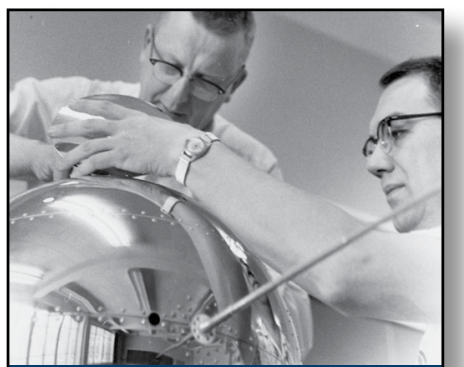

Verner Suomi

The Life and Work of the Founder of Satellite Meteorology

John M. Lewis with Jean M. Phillips,
W Paul Menzel, Thomas H. Vonder Haar, Hans Moosmill

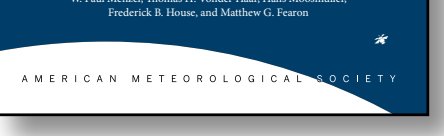

HISTORY

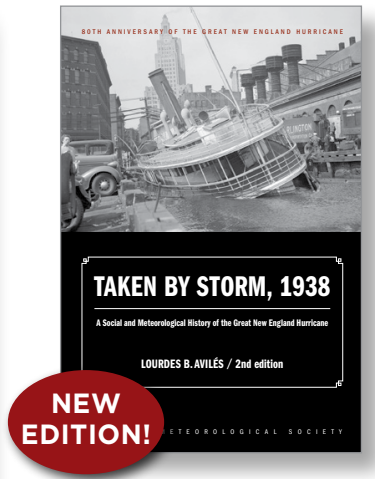

Taken by Storm, 1938:

A Social and Meteorological History of the Great New England Hurricane, 2nd Ed. LOURDES B. AVILÉS

The science behind 80 TH
ANNIVERSARY
AF OF STORM the 1938 Hurricane, which hit New England unannounced, is presented here for the first time along with new data that

sheds light on the motivations of the Weather Bureau forecasters. This compelling history successfully weaves science, historical accounts, and social analyses to create a comprehensive picture of the most powerful and devastating hurricane to hit New England to date.

c) 2018, PAPERBACK, 288 PAGES, ISBN: 978-1-944970-24-6 LIST \$30 MEMBER \$20

\section{A Scientific Peak:}

How Boulder Became a World Center for Space and Atmospheric Science

JOSEPH P. BASSI

How did big science come to Boulder, Colorado? Joe Bassi introduces us to the characters, including Harvard sun-Earth researcher Walter Orr Roberts, and the unexpected brew of politics, passion, and sheer luck that during the Cold War era transformed this "Scientific Siberia" to home of NCAR and NOAA.

(c) 2015, PAPERBACK, 264 PAGES, ISBN: 978-1-935704-85-0 LIST PRICE: $\$ 35.00$ MEMBER PRICE: $\$ 25.00$

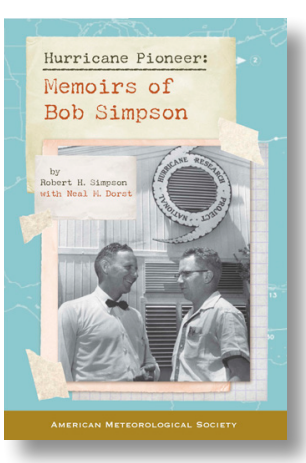
Hurricane Pioneer: Memoirs of Bob Simpson ROBERT H. SIMPSON AND NEAL DORST

In 1951, Bob Simpson rode a plane into a hurricane-just one of the many pioneering exploits you'll find in these memoirs. Bob and his wife Joanne are meteorological icons: Bob was the first director of the National Hurricane Research Project and a director of the National Hurricane Center. He helped to create the Saffir-Simpson Hurricane Scale; the public knows well his Categories 1-5. Proceeds from this book help support the AMS's K. Vic Ooyama Scholarship Fund.

(C) 2015, PAPERBACK, 156 PAGES

ISBN: 978-1-935704-75-1 LIST \$25 MEMBER \$2O 
